E-ISSN: 2663-3361

P-ISSN: 2663-3213

IJRHRM 2020; 2(2): 32-34

Received: 15-10-2020

Accepted: 19-11-2020

Dr. Sonia Delrose Noronha Associate Professor, Srinivas Institute of Management and Commerce, Mangalore,

Karnataka, India
Corresponding Author: Dr. Sonia Delrose Noronha Associate Professor, Srinivas Institute of Management and Commerce, Mangalore, Karnataka, India

\title{
Talent and knowledge management-developing a culture of employee optimization
}

\section{Dr. Sonia Delrose Noronha}

DOI: https://doi.org/10.33545/26633213.2020.v2.i2a.44

\begin{abstract}
Organizations are made up of people: People create value through proven Business Processes, customer service, innovation, sales, and many other significant activities. As an organization strives to meet its business goals, it must ensure that it has a continuous and integrated process for recruiting, selecting, training, developing, supporting, and compensating these valuable Human Assets. While strategic Human Resource remains to be a major focus, organizations are now focused on a new set of strategic issues on improving these processes more efficiently and effectively by means of "competency-based" recruiting instead of sorting through resumes. We are now entering a new era: The Era of the emergence of "Talent and Knowledge Management." Talent management and Knowledge Management is a valuable intangible asset and have a major role in inducing employee productivity. Also termed as Human Capital Management (HCM), Human Resource Information Systems (HRIS) or Human Resource Management Systems (HRMS), and Human Resource Modules will make an organization more competitive. This paper strives to understand Talent Management as an emerging concept and seeks to understand its objectives, process, and critical success factors.
\end{abstract}

Keywords: Talent management, knowledge management, human assets, HCM, HRIS, HRMS

\section{Introduction}

Talent management can be defined as the systematically organized, strategic process of getting the right talent and turning them into world class performers and at the same time the objectives that is looked after the company should be kept in mind ${ }^{[1,5]}$.

First and fore-most the company goals have to be looked into. What do they really need is the question. Then the gaps have to be identified. Identifying the gaps is the most important step. Unless and until the gaps have been identifies it becomes too rudimentary process to go forward with the interview process so it's the need of the hour ${ }^{[6]}$. After identifying the process the right person has to be identified this can be done by talent search programme that is followed by many successful companies and institutions. Once the person with the right talent is identified then bringing them on-board with making them clear with the objectives is highly recommended ${ }^{[7,8]}$. Then training is an integral part of any such programmes. Training them and growing within the system so that they develop the necessary set of skills and expertise with the focus of achieving the goals is the ultimate goal ${ }^{[9,10,11]}$.

Bring the right people on the board for a specific set of long term goals is what the management should do so as to be in the competition. This paper strives to understand Talent Management as an emerging concept and seeks to understand its objectives, process, and critical success factors.

\section{Aims and Objectives}

- To understand the importance of talent management

- To link the importance of talent and knowledge management with that of performance outcome of the institution.

\section{Materials and Methods}

This is qualitative research. Interview was conducted of the managerial staff of different colleges in and around Mangalore.

Data was collected from the interview of the managerial staff in an order to have the opinion about talent management and to get an understanding that whether the particular framework is congruent with the thinking of managers working in Colleges operating in Mangalore. 


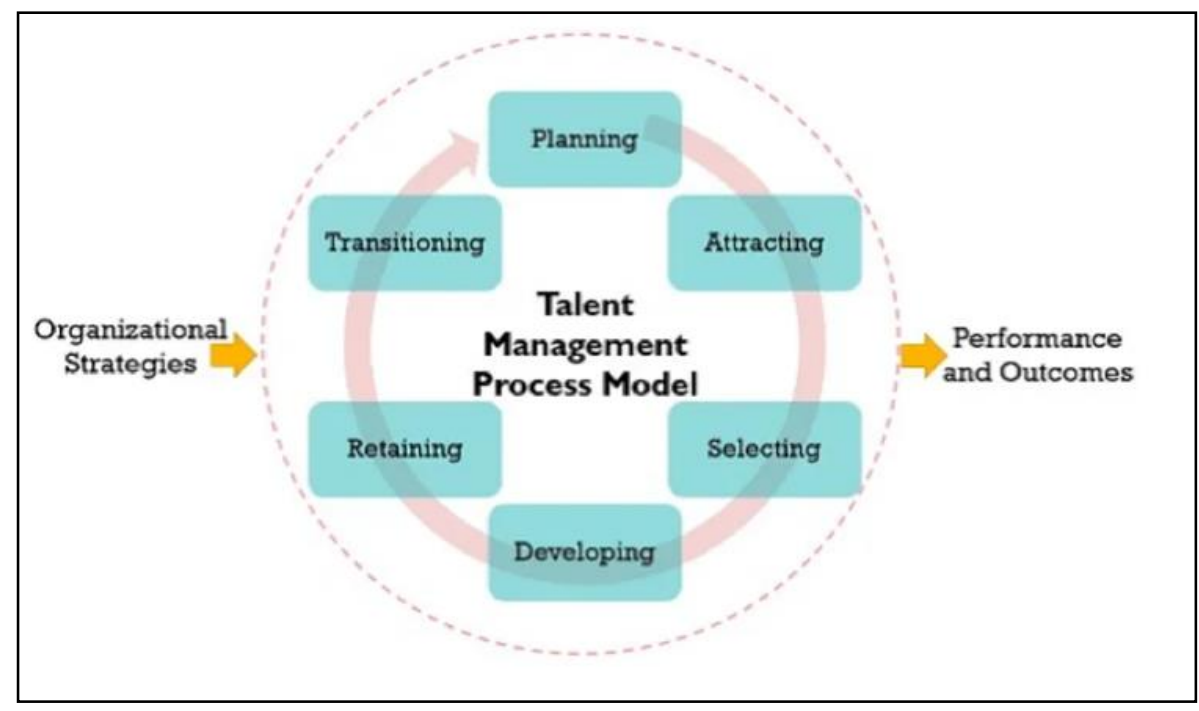

Open-ended interview questionnaire was used to collect the responses. Before conducting interviews, appointments from relevant colleges were taken. Unstructured set of questions were being asked to probe the role of talent management in

colleges effectiveness. Interviewing process has been completed within six month.

\section{Results}

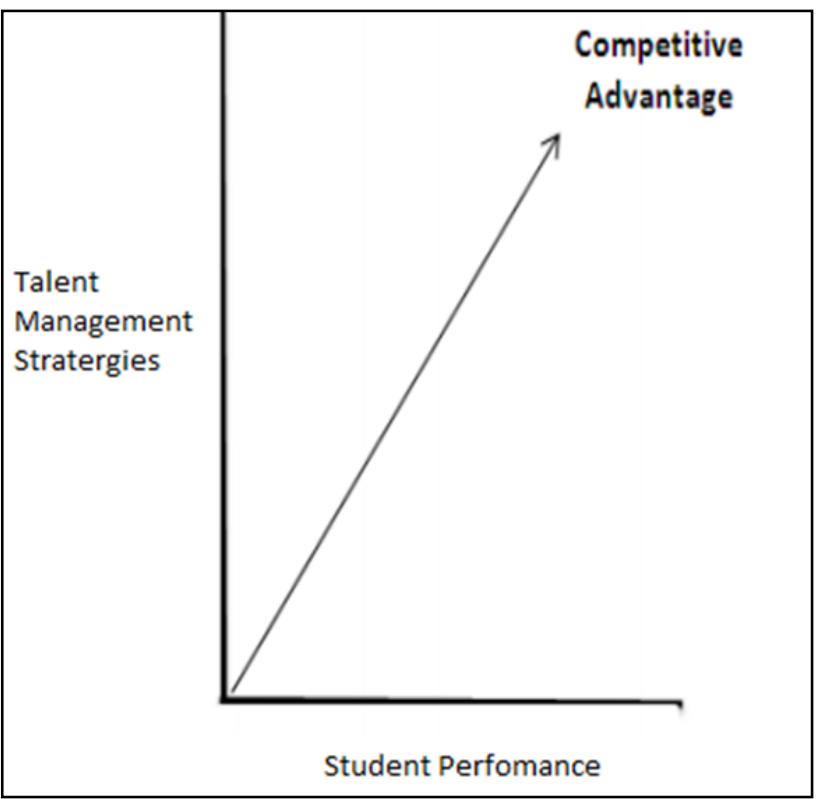

Graph 1: The competitive advantage when talent management strategies and students performance is traced on a graph.

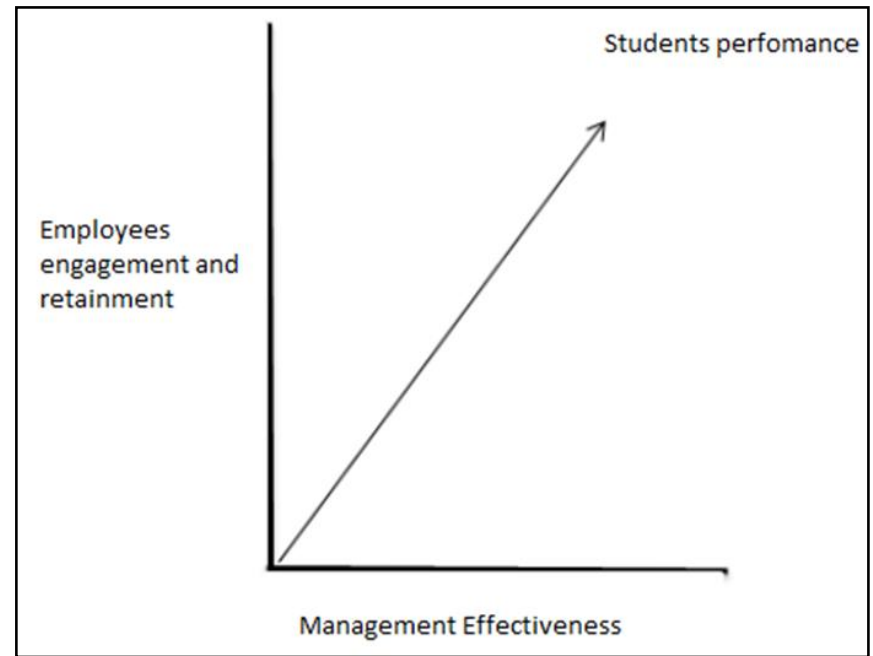

Graph 2: The student performance when talent management effectiveness and when employees attraction, engagement and retainment is practiced. 


\section{Discussion}

The processes of the talent and knowledge management starts with planning includes the planning the capital requirement, formulation of the description of the job for achieving strategic goals and also developing the training programme is needed at this stage.

Then finding the right person for the job is a must. At this stage whether a person should be hired or any person if already there in the system should be found.

Once this is decided then the right person should be interviewed by using a string of methods like tests which includes both the cognitive, psychomotor and effector domains into consideration. The particulars of the tests should be able to throw some light on the capacity of the candidate to achieve the goals.

Then the training of the candidate should be made in such a way that at every step the company's goals and the candidate's roles in achieving those should be kept in mind. This also helps in training the candidate and from day one they will be sure of their roles in the company.

Then comes the difficult part, that is retaining of the employees. It so happens that many a times the company trains them then the other companies just hires the staff by giving them extra incentives. This will hamper the system. This should be avoided by always keeping the employee happy. They should be rendered equal opportunity to grow. Decision making powers, monetary increments at regular intervals and timely promotions ahould be given to the employee. Effective talent management focuses on a collective transformation and evolution of the organization through the growth of individual employees.

Then the last part is finding out the company's performance in terms of results and other criteria are which should be checked. Assessment of this should be done at intervals to find the growth of the institution.

Talent Management Strategy is not a mere checklist of requirements that need to be sufficed - it is a strategy that needs careful implementation, regular checks, and continual improvement.

1. Detailed job descriptions should be in place. No unnecessary person should be involved for the job interview. This helps to lessen the crowd so that proper time can be given to study the person who has the necessary talent.

2. Person-organization fit: hiring a person who does not fit the company's requirement will not do justice for both the candidate and the company. Neither the candidate nor the company will be happy.

3. Collaborate-coach-evolve: This strategy will help in the company's long term goals. The candidate will not only evolve but he/she will be mentoring others. This will help the company in situations like, when the original quits then there are people who has the ability to replace him/her.

4. Reward and recognize right: This will help the company to retain the proper people at job. It should be understood that people make the company and the infrastructure does not. So not only hiring them but recognizing the proper people at the job is also important for the company's long term growth.

5. Opportunities for continuous improvement: Last but not the least proper candidates should be given opportunities to grow. This will help the company to achieve its long term goals with ease.

\section{Conclusion}

The systematically organized, strategic process of getting the right talent and turning them into world class performers and at the same time the objectives of the company should be kept in mind.

\section{References}

1. Yarnall J. Maximising the effectiveness of talent pools: a review of case study literature. Leadership \& Organization Development Journal 2011;32(5):510526.

2. Rani A, Joshi U. A Study of Talent Management as a Strategic Tool for the Organization in Selected Indian IT Companies. European Journal of Business and Management 2012;4(4):20-28.

3. Cappelli P. Talent management for the twenty-first century. harvard business review 2008;86(3):74.

4. Scullion H, Collings D. Global talent management. Taylor \& Francis 2010.

5. Makela K, Björkman I, Ehrnrooth M. How do MNCs establish their talent pools? Influences on individuals' likelihood of being labeled as talent. Journal of World Business 2010;45(2):134-142.

6. Guthridge M, Komm AB, Lawson E. Making talent a strategic priority. McKinsey Quarterly 2008;1:48.

7. Hanif MI, Yunfei S. The role of talent management and HR generic strategies for talent retention. African Journal of Business Management 2013;7(29):28272835.

8. Maria-Madela A, Mirabela-Constanţa M. Talent management-a strategic priority. Leadership 2009;3(2):4.

9. Armstrong M. A handbook of human resource management practice. Kogan Page Limited. [20] Blass, E. (Ed.). (2009). Talent management: Cases and commentary. Basingstoke,, UK: Palgrave Macmillan 2003.

10. Low $P$ Talent management, the Confucian way. Leadership \& Organizational Management Journal 2010;(3):28-37.

11. Sheehan M. Developing managerial talent: Exploring the link between management talent and perceived performance in multinational corporations (MNCs). European Journal of Training and Development 2012;36(1):66-85 